\title{
Representações Sociais sobre o Trabalho do Segundo Professor na Educação Inclusiva
}

\author{
Representaciones Sociales sobre el Trabajo del Segundo Maestro em Educación \\ Inclusiva
}

\section{Social Representations about the Work of the Second Teacher in Inclusive Education}

\author{
Natalia Silveira Lima \\ Secretaria Municipal de Educação de Concórdia, Concórdia - SC/Brasil \\ ORCID: 0000-0003-0106-9213 \\ E-mail: natilima1973@gmail.com
}

Lísia Regina Ferreira

Universidade Federal da Fronteira Sul (UFFS), Chapecó - SC/Brasil

ORCID: 0000-0003-1028-8397

E-mail: lisia.ferreira@uffs.edu.br

\begin{abstract}
Resumo
Este artigo apresenta um relato de pesquisa que teve como objetivo identificar os elementos presentes na formação de representações sociais, por professores regentes de anos iniciais, sobre o trabalho do segundo professor, na perspectiva da Educação Inclusiva. A educação de sujeitos com deficiência no ensino regular, tem desafiado os sistemas de ensino, dando lugar a um novo profissional na sala de aula, o segundo professor. A Teoria das Representações Sociais foi utilizada como referencial teórico-metodológico, constituindo-se num importante meio de investigação, no qual buscamos identificar e analisar os processos de objetivação e ancoragem presentes nas representações sociais, por professores regentes de anos iniciais do Ensino Fundamental, sobre o trabalho do segundo professor. Foram entrevistados 15 professores regentes. A análise dos dados foi realizada mediante uma análise lexical de Classificação Hierárquica Descendente. A análise dos dados coletados permitiu estabelecer relações e considerações sobre as percepções e os sentidos que são atribuídos ao trabalho do segundo professor por parte dos professores regentes, apresentando as ancoragens e objetivações que estão na formação e sustentação de suas representações. Considerando que a atuação do segundo professor é uma prática recente, destacamos que as imagens sobre este professor não estão totalmente definidas. O imaginário dos professores regentes está permeado por ancoragens que dotam o segundo professor de condições de controle, vigilância, auxílio e cuidados dos educandos com deficiência.
\end{abstract}

Palavras-chaves: Representações sociais; Segundo professor; Inclusão escolar.

\section{Resumen}

Este artículo presenta una investigación que tuvo como objetivo identificar los elementos presentes en la formación de las representaciones sociales, por parte de los docentes que fueron maestros de los primeros años, sobre el trabajo del segundo docente, desde la perspectiva de la Educación Inclusiva. La educación de los sujetos con discapacidad en la educación regular ha desafiado los sistemas educativos, dando espacio a un nuevo profesional en clase, el segundo maestro. La Teoría de las representaciones sociales fue utilizada como un marco teórico-metodológico, constituyendo un importante medio de investigación, en el cual buscamos identificar y analizar los procesos de objetivación y anclaje presentes en las representaciones sociales, por maestros de los primeros años de la escuela primaria, acerca del trabajo del segundo maestro. Han sido entrevistados 15 maestros regentes. El análisis de los datos se ha realizado mediante un análisis léxico de clasificación jerárquica descendente. El análisis de los datos recopilados permitió establecer relaciones $\mathrm{y}$ consideraciones sobre las percepciones y significados que los maestros regentes atribuyen al trabajo del segundo maestro, presentando los anclajes y objetivaciones que se encuentran en la formación y el apoyo de sus representaciones. Considerando que el desempeño del segundo maestro es una práctica reciente, enfatizamos que las imágenes sobre este maestro no están completamente definidas. Lo imaginario de los maestros regentes está permeado por anclas que permiten al segundo maestro condiciones de control, vigilancia, 
asistencia y atención para estudiantes con discapacidades.

Palabras clave: Representaciones sociales; Segundo maestro; Inclusión escolar.

\begin{abstract}
This article presents a research report that aimed to identify the elements present in the formation of social representations, by teachers who were teachers of early years, about the work of the second teacher, from the perspective of Inclusive Education. The education of students with disabilities in regular education has challenged the educational systems, giving way to a new professional in the classroom, the second teacher. The Social Representations Theory was used as a theoreticalmethodological framework, which constituted an important tool to identify and to analyze the objectivation
\end{abstract}

\section{Introdução}

Atender à política brasileira de inclusão escolar, que estabelece o direito de todos os educandos ao acesso e permanência na escola com qualidade, tem sido um grande desafio para os sistemas de ensino, tendo em vista que para atender as diferentes formas de constituição humana, de estilos e ritmos de aprendizagem, tem requerido desses sistemas uma nova forma de conceber o espaço educativo, principalmente o contexto de sala de aula.

Nesta perspectiva, a Educação Inclusiva constitui um novo paradigma educacional fundamentado na concepção de direitos humanos, que concebe igualdade e diferença como valores indissociáveis, e a escola como um espaço onde educandos com ou sem deficiência compartilham saberes e experiências (Brasil, 2010). Este paradigma tem desafiado os sistemas de ensino, as escolas e, principalmente os professores, a darem respostas à nova realidade do contexto escolar. A escola inclusiva reivindica ações educativas que respondam de maneira eficaz à diversidade de todos os educandos.

Atuar pedagogicamente em contextos reconhecidos como diversificados, onde as singularidades de cada educando devem ser consideradas, propõe uma ruptura de modelos pedagógicos que, até então, atuavam de forma and the anchorage processes present in social representations. Fifteen teachers were interviewed. A lexical analysis of descending hierarchical classification was performed on data analysis, allowing to establish relationships and considerations about the perceptions and meanings attributed to the work of the second teacher by the participants, revealing the anchorages and objectivations that are in the formation and support of their representations. Considering that the role of the second teacher is a recent practice, we emphasize that the images about this teacher are not fully defined. The teachers' imaginary is permeated by anchorages that attribute to the second teacher conditions of control, surveillance, assistance and care for students with disabilities.

Keywords: Social representantions; Second teacher; School inclusion.

homogênea sem considerar tais especificidades. Visando atender essa fragilidade pedagógica, a Educação do Estado de Santa Catarina instituiu por meio de dispositivos legais, a figura do segundo professor. Este passa a ser visto como o "professor do aluno especial", aquele sine qua non será possível promover efetivamente tal processo inclusivo. De acordo com a Lei 17.143/2017 o segundo professor é definido como o profissional da área de educação especial que acompanha e atua de forma conjunta com o professor titular em sala de aula, com o objetivo de atender aos educandos que possuem deficiência e estão matriculados na educação básica regular das escolas públicas de Santa Catarina (Lei n. 17.143, 2017).

Considerando os limites dos sistemas educativos para atenderem as perspectivas da educação inclusiva, a contratação de professores para apoiar, compartilhar e colaborar com as atividades cotidianas da escola na inclusão de educandos com deficiência representa um importante avanço na política pública. A atuação do segundo professor pode representar um avanço no trabalho pedagógico na perspectiva da inclusão escolar, na medida em que atua de forma conjunta e compartilhada na regência de turma onde tenha a matrícula de educandos com deficiência. Por outro lado, seria um retrocesso, se a atuação do segundo professor se 
caracterizar em outra forma de expressão do ensino especial, fundamentado no modelo clínico-médico, na medida em que o trabalho pedagógico se faz individualizado e descontextualizado do restante da turma, tornando o educando com deficiência um sujeito à parte na sala de aula, priorizando sua condição de deficiência em detrimento de suas possibilidades de aprendizagem (Beyer, 2006).

O trabalho pedagógico pautado na docência compartilhada deve atuar sempre no contexto do grupo, procurando, também, atender necessidades eventuais que os demais alunos possam apresentar, assim como, é importante que ocorram trocas entre os professores (Beyer, 2006).

Neste contexto educacional, é fundamental que o segundo professor tenha conhecimentos e clareza sobre o seu papel diante da perspectiva da educação inclusiva. A necessidade de mudança nas práticas pedagógicas diante da inclusão escolar, pressupõe novos posicionamentos, novas possibilidades de docência. Esta nova forma de atuação pedagógica precisa se tornar uma prática conhecida, reestruturada e principalmente assimilada por parte dos professores.

Evocar a temática da docência compartilhada, debater, comunicar e compartilhar ideias, contribui para os processos de assimilação da nova prática pedagógica, conduzindo para a prática de novas práticas frente ao trabalho docente em contextos educativos heterogêneos e de múltiplas tensões. Colocar o trabalho do segundo professor no contexto histórico e conjuntural das relações de forças que procuram construir identidades coletivas no contexto educativo, permite captar o movimento de reconstrução do fazer pedagógico na prática cotidiana da escola.

Diante deste contexto polêmico, conflituoso e desafiante proposto pelo paradigma da educação inclusiva, buscamos por meio da Teoria das Representações Sociais um referencial teórico-metodológico para a descrição e explicação dos fenômenos presentes na relação dos professores envolvidos na docência compartilhada, pois estes fenômenos reproduzem pensamentos e práticas comuns a um grupo de indivíduos.

Neste sentido, o problema investigado por esta pesquisa foi: Que elementos e relações podem ser considerados indicadores de formação de representações sociais, por professores regentes de anos iniciais, sobre o trabalho do segundo professor, na perspectiva da Educação Inclusiva? Frente ao problema apresentado, a pesquisa teve como objetivo identificar os elementos presentes na formação de representações sociais, por professores regentes de anos iniciais, sobre o trabalho do segundo professor, na perspectiva da Educação Inclusiva. Para tanto, buscamos compreender como os professores regentes de anos iniciais percebem o trabalho do segundo professor; identificar onde estão sendo ancorados os sentidos atribuídos, pelos professores regentes, ao trabalho do segundo professor e identificar os elementos indicadores de formação de representações sociais.

A Teoria das Representações Sociais (TRS) constitui-se em uma teoria psicossocial, por meio da qual procura-se compreender como o sujeito, inserido num grupo, e como o próprio grupo chegam ao conhecimento, ou seja, como os sujeitos formam conceitos, ideias, valores e representações sobre os objetos e qual a relação destes com a realidade. Segundo Moscovici (2003) não são realidades, mas formas de representações da realidade. Portanto, em função dessas representações que se movem indivíduos e coletividades. Saber como se formam e operam essas representações é papel essencial da TRS.

Uma das finalidades da TRS é tornar familiar aquilo que é não-familiar, ou seja, tornar conhecido algo até então desconhecido, classificar e nomear novos conhecimentos, fenômenos e ideias a partir de práticas, conhecimentos, valores e teorias já existentes e assimilados. A esses processos, Moscovici (2003) denomina de "objetivação e ancoragem" e, destaca que os mesmos se desenvolvem de forma contínua, concomitantes e inter- 
relacionados, constituindo e dando sentido à representação social. $O$ autor apresenta a "objetivação e a ancoragem" como processos sociocognitivos que estão na formação e sustentação das representações sociais.

Os processos de objetivação e ancoragem, constituem-se processos formadores de representações sociais. Trata-se, portanto, da possibilidade de tornar os conhecimentos em algo prático, adequado à vida cotidiana e social, ou seja, compreender como a produção de conhecimentos plurais constitui e reforça a identidade dos grupos, como influi em suas práticas e como estas reconstituem seu pensamento, produzindo uma visão comum sobre as coisas, o mundo e a realidade. Por isso, é importante que se dê de forma comunicativa e difusa, através dos discursos e dos sentidos que este contém. Assim, verifica-se que as representações sociais, enquanto forma de pensamento social prático, são veiculadas e manifestadas no cotidiano por meio dos discursos, atitudes, comportamentos e práticas sociais.

O processo de objetivação tem como proposição objetivar ideias, isto é, transformar aquilo que está na mente (abstrato) em algo que exista no mundo físico (concreto). É dar um sentido icônico a uma ideia. A objetivação trata da organização dos elementos que constituem as representações e ao percurso por meio do qual estes elementos se materializam e se constituem expressões de uma realidade pensada como natural. Para tanto, o processo de objetivação envolve três momentos que ocorrem simultaneamente: a construção seletiva, a esquematização e a naturalização (Moscovici, 2003).

A seleção é o processo por meio do qual serão elencadas as informações ou elementos referentes ao objeto a ser representado. Essa seleção não é realizada de forma neutra ou arbitrária, mas sofre influências de critérios socioculturais e normativos. A formação do núcleo figurativo, tem por finalidade a inserção de uma qualidade icônica em uma ideia. Segundo Moscovici (2003, p.72) "o núcleo figurativo é como um complexo de imagens que reproduzem visivelmente um complexo de ideias". O processo de elaboração das representações sociais está significativamente relacionado à formação do núcleo figurativo. No processo de naturalização, o sujeito absorve e incorpora em seu discurso os elementos do núcleo figurativo, esquecendo que outrora já lhes foram estranhos e originários de outros. É no processo de naturalização que esses elementos são apropriados pelos sujeitos, as imagens passam a fazer parte da realidade e do senso comum (Nova; Machado, 2014).

O processo de ancoragem é um mecanismo que procura ancorar ideias nãofamiliares, reduzindo-as a categorias e a imagens comuns e familiares. Esse processo refere-se ao fato de que, qualquer construção ou relação com um novo objeto ou informação, requer pontos de referências, experiências e pensamentos já adquiridos e estabelecidos (Vala, 2006). Assim, o ato de ancorar, nos remete ao ato de representar, um meio de transferir o que nos é perturbador e ameaçador, do exterior para o interior, do desconhecido para algo próximo. Essa transferência é efetivada pela separação de conceitos e percepções interligados, onde o incomum se torna comum, onde o desconhecido se inclui numa categoria já conhecida (Moscovici, 2003). A ancoragem dá suporte ao processo de formação de representações sociais, na medida em que estas resultam sempre de um esforço de tornar comum e real algo que até então era incomum. Para tanto fazemos uma série de ajustes, tornando concreto, aquilo que parecia ser abstrato. Nesse processo de ancoragem, as imagens, ideias, conhecimentos e categorias com os quais compreendemos o não-familiar, trazem-nos de volta ao que já conhecíamos e com o qual já estávamos familiarizados, dandonos, assim, uma impressão segura de algo já visto e conhecido.

Neste sentido, a Teoria das Representações Sociais foi utilizada como referencial teórico-metodológico para o desenvolvimento desta pesquisa, constituindose num importante meio de investigação, no qual buscamos identificar os elementos presentes na formação de representações 
sociais, por professores regentes de anos iniciais do Ensino Fundamental, sobre o trabalho do segundo professor na perspectiva da Educação Inclusiva.

\section{Método}

Trata-se de uma pesquisa qualitativa, que contou com a participação de 15 professoras regentes de anos iniciais que se encontravam em efetiva atividade docente e atuavam, conjuntamente, com o segundo professor em turmas de anos iniciais do Ensino Fundamental. Os professores participantes da pesquisa foram identificados como: suj 01, suj 02, suj 03, suj 04, suj 05, suj 06, suj 07, suj 08, suj 09, suj 10, suj 11, suj 12, suj 13, suj 14 e suj 15.

O instrumento de coleta de dados utilizado para o desenvolvimento desta pesquisa foi a entrevista semiestruturada, a qual contou com um roteiro pré-definido, contemplando questões que atendiam às funções descritivas, prescritivas e avaliativas das representações do objeto pesquisado. As entrevistas foram gravadas, mediante autorização dos participantes, transcritas e transformadas em textos para a realização da análise dos dados.

A análise dos dados foi realizada mediante uma análise lexical de Classificação Hierárquica Descendente - CHD. Para a realização das análises CHD foi utilizado o software IRAMUTEQ (Interface de R pour les Analyses Multidimensionnelles de Textes et de Questionnaires), o qual realizou uma análise estatística sobre o corpus textual construído a partir das entrevistas. O IRAMUTEQ é um software gratuito, com fonte aberta, que possibilita a realização de análises estatísticas sobre corpus textuais e sobre quadros indivíduos/palavras (Camargo \& Justo, 2013).

Considerando os aspectos éticos previstos na Resolução 466/2012 do Conselho Nacional de Saúde, que orienta as pesquisas que envolvem seres humanos, esta pesquisa foi enviada ao Comitê de Ética em Pesquisa em
Seres Humanos da Universidade Federal da Fronteira Sul - UFFS para que fosse avaliado. A pesquisa foi aprovada com o Certificado de Apresentação para Apreciação Ética - CAAE 62445416.0.0000.5564 e parecer $\mathrm{n}^{\circ}$ 3.263.628.

\section{Resultados}

$\mathrm{Na}$ análise de CHD, o software realizou uma análise quantitativa dos dados textuais e possibilitou obter uma ampla visão sobre o material discursivo. Possibilitou, ainda, a análise qualitativa, por meio de um dendograma, que apresenta as partições feitas no corpus, até que se chegasse às classes finais.

Lendo o Dendograma, da esquerda para a direita, é possível observar que, num primeiro momento, o corpus foi dividido em dois subcorpus, resultando na classe 5, com 14,7\% de segmentos de textos aproveitados. Num segundo momento, um subcorpus foi dividido em dois, resultando, de um lado, as classes $1 \mathrm{e}$ 3 , que somam $40,4 \%$ de segmentos aproveitados e do outro as classes 4 e 2 , que somam $44,9 \%$ dos segmentos aproveitados. As repartições finalizaram-se, pois, as 5 classes mostraram-se estáveis.

Além do Dendograma, o programa possibilitou identificar o conteúdo lexical de cada uma das classes, conforme apresentado na figura 2.

A análise textual realizada pelo programa IRAMUTEQ possibilitou a identificação das categorias a serem analisadas (Figura 3). A partir das análises das categorias buscou-se compreender como as representações sociais sobre o trabalho do segundo professor estão sendo construídas, a partir das experiências dos professores regentes de anos iniciais envolvidos na docência compartilhada.

O conteúdo lexical apresentado pelas classes foi dividido em três grandes categorias, sendo que duas apresentam subdivisões conforme a figura 3 . 
Figura 1. Dendograma

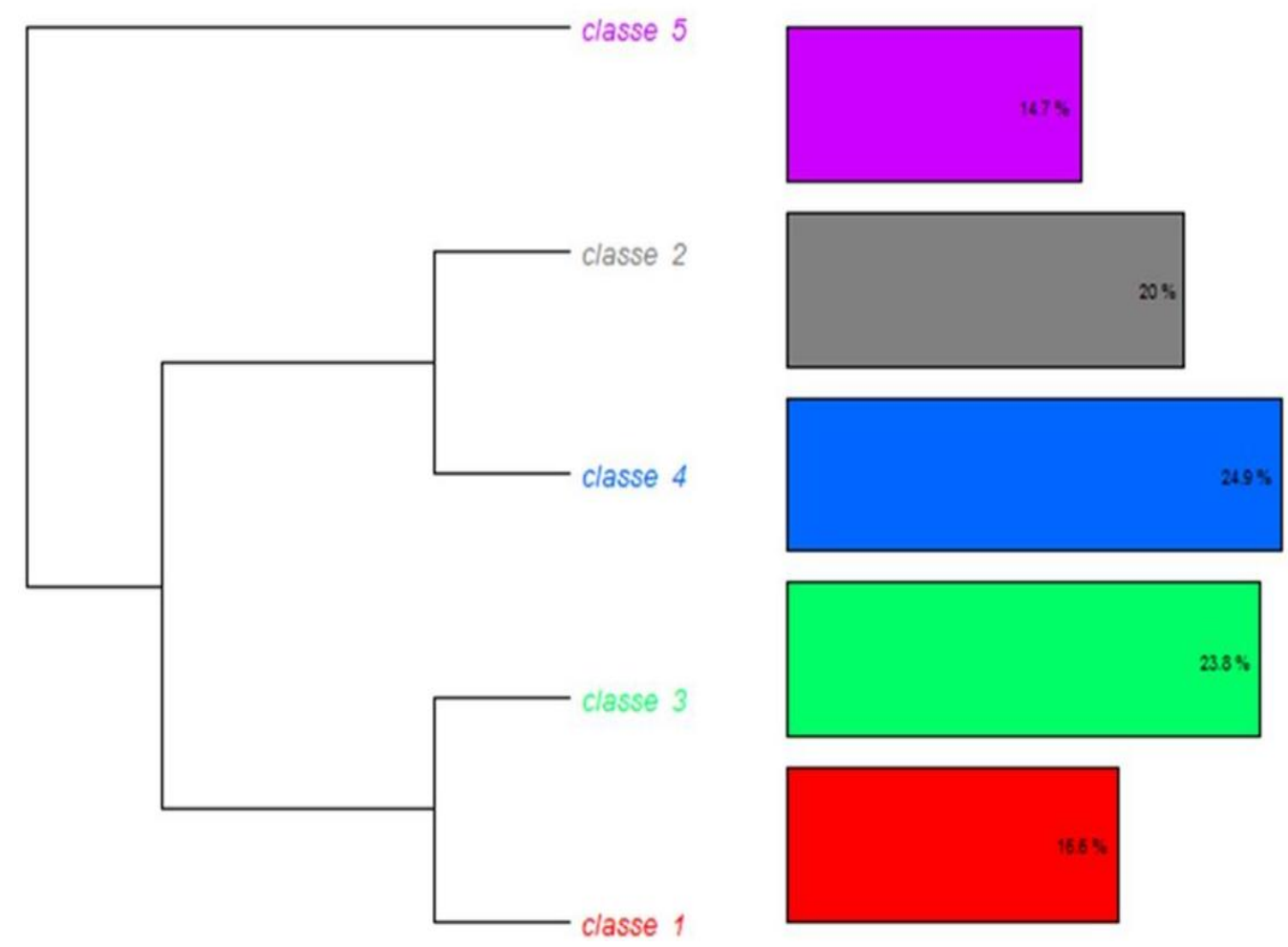

Fonte: IRAMUTEQ.

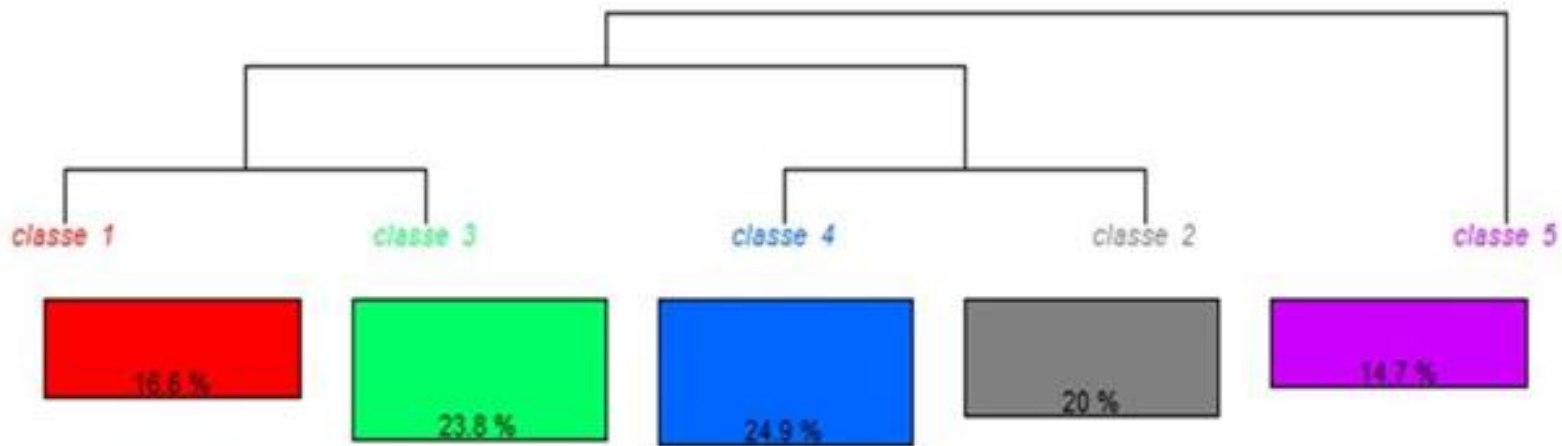

\begin{tabular}{|c|c|c|c|c|}
\hline $\begin{array}{l}\text { coisa } \\
\text { perder }\end{array}$ & $\begin{array}{l}\text { trabalhar } \\
\text { mensagem }\end{array}$ & $\begin{array}{l}\text { trabalho } \\
\text { segundo professor }\end{array}$ & $\begin{array}{l}\text { atividade } \\
\text { planejamento }\end{array}$ & $\begin{array}{l}\text { escola } \\
\text { apae }\end{array}$ \\
\hline atrapalhar & sentir & caracteristica & conteúdo & apde \\
\hline aprender & noticia & funçẳo & $\begin{array}{l}\text { junta } \\
\text { segunda professora }\end{array}$ & $\begin{array}{l}\text { tema } \\
\text { época }\end{array}$ \\
\hline dizer & segundo professor & $\begin{array}{l}\text { diferença } \\
\text { falta }\end{array}$ & planejar & escolar \\
\hline querer & experièncis & $\begin{array}{l}\text { alta } \\
\text { aluno }\end{array}$ & pucar - & frequentar \\
\hline acabar & receber & atribuir & $\begin{array}{l}\text { Organicar } \\
\text { mesmo }\end{array}$ & contexto \\
\hline ficar & contato & dificuldade & adagtar & discutir \\
\hline conseguir & $\begin{array}{l}\text { bemt } \\
\text { afoidade }\end{array}$ & $\begin{array}{l}\text { dever } \\
\text { envolvimento }\end{array}$ & exemplo & inclusäo \\
\hline $\begin{array}{l}\text { meter } \\
\text { tirar }\end{array}$ & Dessca & chegada & pertios & inicio. \\
\hline legal & vender & $\begin{array}{l}\text { perceber } \\
\text { colocar }\end{array}$ & das & reuniăo \\
\hline impressão & sbertura & $\begin{array}{l}\text { colocar } \\
\text { conhecimento }\end{array}$ & aub & $\begin{array}{l}\text { orientador } \\
\text { reacis }\end{array}$ \\
\hline parecer & vigist & professor_regente & $\begin{array}{l}\text { exmunicat } \\
\text { secessigino }\end{array}$ & lembear \\
\hline
\end{tabular}

Figura 2. Dendograma da CHD com as partições e conteúdo lexical Fonte: Dados gerados pelo IRAMUTEQ a partir da análise dos resultados obtidos nas entrevistas. 


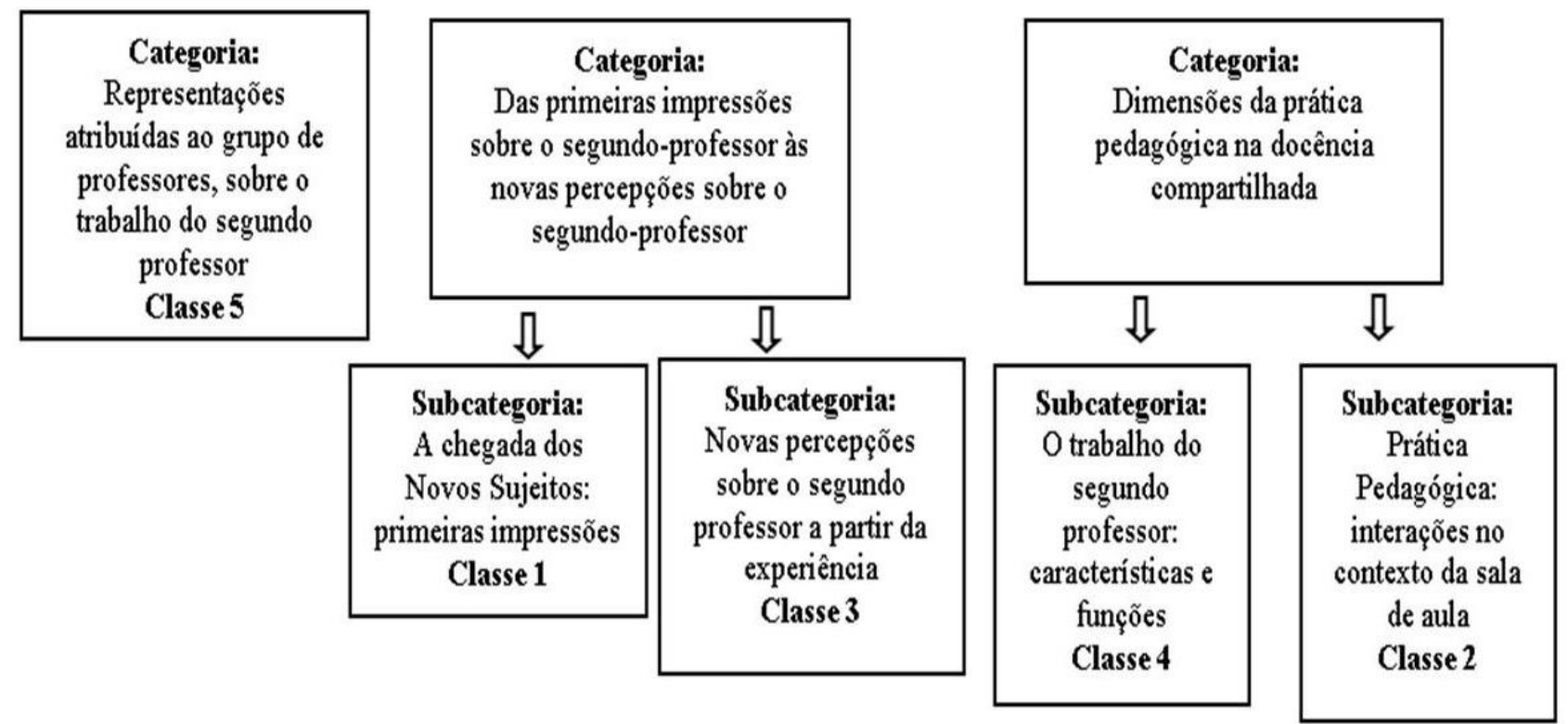

Figura 3. Categorias identificadas a partir do conteúdo lexical gerado pelas classes

Fonte: Figura elaborada pelas autoras

\section{Discussão}

A categoria representações atribuídas ao grupo de professores sobre o trabalho do segundo professor (classe 5) apresenta os conteúdos presentes nos discursos dos grupos de professores sobre o trabalho do segundo professor.

Os conteúdos desta classe fazem referência à escola regular enquanto novo espaço de escolarização e atenção às pessoas com deficiência, as quais, até a implantação da política de inclusão, frequentavam, especificamente, as instituições e escolas especiais, como as Associações de Pais e Amigos dos Excepcionais - APAEs.

As entrevistas revelaram o impacto, as dúvidas, as resistências e as preocupações dos professores diante da chegada dos educandos oriundos das APAEs, na escola regular. Para o grupo de professores, o trabalho do segundo professor representa a necessidade de ter este profissional no contexto escolar, para atender às necessidades educacionais dos educandos com deficiência. $\mathrm{Na}$ perspectiva dos entrevistados, o grupo de professores compreende a escola como despreparada e sem as adaptações necessárias para receber esses educandos, sendo as instituições e escolas especializadas as mais adequadas para atendê- los com qualidade, recursos e profissionais especializados.

Quando veio a fala de que as crianças que frequentavam a APAE teriam que estar matriculadas nas escolas públicas municipais as reações diante deste tema num primeiro momento foram de uma situação impactante. $O$ que vamos fazer com essas crianças? Nós não estamos preparados para atender. (suj. 01).

Desde o começo, quando começaram a frequentar os alunos que vinham da APAE, nós professores tivemos uma preocupação enquanto escola. Diante desta realidade eu senti que havia uma preocupação por parte da escola em buscar formas para melhor atender esses alunos que estavam vindo da APAE mesmo sabendo que a escola não tinha toda a estrutura que uma APAE tem e nem os profissionais. (suj. 02).

Na verdade, a educação não consegue atingir essas crianças em algumas situações. No caso de criança que tem síndromes mais grave, por mais que o professor tente não tem o conhecimento, ou até mesmo espaço 
físico para direcionar essa criança para uma massagem, um alongamento, um trocador apropriado. Esses casos eu acredito que tenham que ir para uma outra instituição. Então, as instituições que têm todo esse aparato é que vão facilitar a qualidade de vida de certas deficiências. Não que esses alunos não possam frequentar o ensino regular, mas, é que aqui a nossa condição clínica não existe. É inexistente na educação, na sala de aula, na escola. (suj. 06).

Estas percepções estão ancoradas na concepção de dicotomia da educação, a qual partia do pressuposto de que deveria existir dois sistemas de educação: o regular e o especial. Sendo o sistema regular destinado aos educandos que apresentavam padrões normais de desenvolvimento e aprendizagem e o sistema especial, proposto para aqueles que não apresentavam capacidade acadêmica para frequentar a escola comum em razão de sua deficiência (Sassaki, 2005).

A educação de pessoas com deficiência se organizou, tradicionalmente, como atendimento substitutivo ao ensino comum, evidenciando diferentes concepções que fomentaram à criação de instituições especializadas e escolas especiais. Fundamentadas no conceito de normalidade/anormalidade, estas instituições determinavam formas de atendimento fortemente ancoradas em testes e diagnósticos, os quais definiam as práticas escolares para os educandos com deficiência (Brasil, 2010).

Os educandos com deficiência intelectual têm uma maneira singular de lidar com a aprendizagem, a qual não corresponde à maneira que a escola regular preconiza. Estes, por muito tempo, foram rotulados, estigmatizados e considerados incapazes de adquirirem conhecimentos acadêmicos, pois tratavam-se de pessoas com comprometimento intelectual. Devido a essa compreensão, tiveram suas trajetórias escolares construídas num sistema educacional à parte da educação regular, ou seja, em um sistema especial que procurou garantir as aprendizagens funcionais e a atenção às condições de vida prática. Estes educandos carregam estigmas e preconceitos que marcam suas histórias e trajetórias de vida como sujeitos incapazes, desacreditados, dotados de limites e impossibilidades. Esses estigmas e estereótipos são fenômenos psicossociais que se constituem em mecanismos de defesa frente à deficiência e aos processos inclusivos, e se configuram em barreiras atitudinais que justificam as resistências da escola e dos professores para enfrentarem novos desafios e mudanças na forma de organizarem e definirem suas práticas pedagógicas (Mantoan, 2010; Amaral, 1995).

A nova perspectiva de inclusão escolar, rompe a dicotomia do sistema de ensino e reconhece a escola regular como a escola obrigatória e comum à todos os educandos, independentemente de suas condições física, cognitivas e sociais. Essa nova realidade lança desafios aos professores que, ao atuarem junto aos educandos com deficiência, terão que descobrir novos caminhos para ensinar, planejar, avaliar e conhecer os recursos de aprendizagem desses educandos (Oliveira, Braun, \& Lara, 2013).

Outro elemento destacado pelo grupo de professores refere-se ao fato de que, antes da implantação das leis e das políticas inclusivas, o tema sobre inclusão e o trabalho do segundo professor era pouco debatido no contexto escolar. Os momentos de formação continuada, reuniões e estudos pedagógicos não contemplavam conhecimentos sobre o trabalho educativo em contextos diversificados, principalmente, sobre a inclusão de pessoas com deficiência, como destaca o suj 04 em sua fala: "pouco se comentava sobre o segundo professor e sobre esses alunos, porque eles tinham a APAE. Nesse período eles iam lá, não tínhamos contato com eles aqui”.

Historicamente, o professor se constituiu enquanto detentor dos saberes e dos espaços no contexto da escola tradicional. Contrapondo esta concepção, a escola, na perspectiva da educação inclusiva, propõe 
atuação de professores dispostos a atuarem na complexidade das relações humanas e das condições estruturais de uma escola que pretende se constituir inclusiva. Tal condição desperta sentimento de insegurança e de medos por parte dos professores, pois estão passíveis de olharem e serem olhados. Com a inclusão dos educandos e com a inserção do segundo professor, a necessidade de estudos, diálogos e abordagens sobre o trabalho do segundo professor no contexto escolar é uma realidade, considerando que serão por meio destes intercâmbios comunicativos, estabelecidos nos grupos de professores, que irão emergir as compreensões e os sentidos atribuídos ao trabalho desse profissional, de modo a ser assimilado e posto em prática no cotidiano escolar.

A categoria de análise das primeiras impressões sobre o segundo professor às novas percepções sobre o segundo professor foi subdividida em duas subcategorias, definidas como: a chegada dos novos sujeitos: primeiras impressões (classe 1) e novas percepções sobre o segundo professor a partir da experiência (classe 3).

A subcategoria a chegada dos novos sujeitos: primeiras impressões (classe 1) apresenta uma dimensão avaliativa sobre a inserção do segundo professor e do educando com deficiência no contexto escolar.

Os elementos desta classe expressam as primeiras impressões apresentadas pelos professores regentes, sujeitos da pesquisa, diante da chegada do novo professor, bem como do educando com deficiência. As primeiras impressões apresentadas pelos professores regentes referem-se às tensões, a insegurança e dúvidas diante do novo professor e dos educandos com deficiência.

Será que ele vai me ajudar ou vai atrapalhar? Ou ficar se metendo ou alguma coisa desse gênero? A gente fica com um pouco de receio no início. Tem essa primeira impressão. (suj. 09).
A gente acha que o segundo professor vai alterar, vai se meter, opinar ou tirar o que cabe ao professor regente. (suj. 06).

É uma situação difícil ficar com uma criança assim. As coisas não são iguais, numa turma regular, onde tem criança com deficiência, eu vejo assim. Parece que a gente fica numa tensão de que essa criança tem que aprender junto, mas é difícil. Eu tenho as minhas dúvidas, se a criança vai ser inclusa, ou se ela vai apenas estar ali. Na verdade, eu não sei quem ganha e quem perde. Se é o aluno que está ali, querendo ou pedindo para estar, ou se são os alunos que querem estar tranquilo para aprender. (suj. 04).

Os dados revelaram uma representação do segundo professor, como alguém que poderá atrapalhar, intervir, opinar e interferir no trabalho do professor regente. As falas também descrevem o educando com deficiência como uma criança diferente, no entanto, essa diferença, é compreendida de forma negativa que interfere no andamento do trabalho pedagógico e na aprendizagem dos demais educandos.

As análises evidenciaram a dificuldade dos professores regentes em lidar com as diferenças no contexto da sala de aula, tanto em relação aos educandos com deficiência, quanto às situações de interação junto ao segundo professor. Os professores rejeitam a nova proposta inclusiva, em sua prática, por medo e defesa. Alguns acreditam que não sabem trabalhar com os alunos com deficiência, enquanto outros justificam que estes podem prejudicar o andamento e o desenvolvimento da classe (Brien \& Brien, 1994 citado por Stainback \& Stainback, 1999).

Essas representações ancoram-se nas ideias e concepções que consideram os alunos com deficiência, sujeitos ameaçadores, incapazes de aprenderem, e que não conseguem dar respostas às expectativas educacionais e 
sociais. Estas ancoragens refletem, de forma significativa, no processo de inclusão/exclusão, uma vez que, tanto o educando com deficiência, quanto o segundo professor vivenciam um processo de segregação, exclusão e individualização do processo pedagógico.

Esse cenário de tensões e dificuldades reflete nas tomadas de decisões e nas atitudes desses professores diante da inclusão escolar. Nesse sentido, Denari (2013), argumenta que os professores não podem se perder na incerteza sobre o que fazer diante das novas demandas educacionais. A educação na e para a diversidade envolve uma mudança pedagógica, na qual a relação tradicional entre os sujeitos que ensinam e aprendem deva ser reconsiderada e ressignificada.

A subcategoria novas percepções sobre o trabalho do segundo professor a partir da experiência, apresenta uma dimensão prescritiva sobre o trabalho do segundo professor. Os elementos desta classe apresentam as percepções dos professores regentes sobre o trabalho do segundo professor, construídas a partir das experiências vivenciadas na interação com esse professor. Essa dinâmica possibilitou compreender como os conceitos e as ideias sobre o trabalho do segundo professor estão sendo reelaborados e comunicados pelos professores regentes, a partir da experiência e da relação concreta com o segundo professor. Trata-se da dinâmica em que, o que é percebido substitui o que é concebido, contribuindo, dessa forma, para uma mudança de representação, na qual, as primeiras impressões geradas, inicialmente, pelos sentimentos de dúvidas e inseguranças passam a ser substituídas pelas novas percepções (Moscovici, 2003).

Será que vai me ajudar ou não? Ao invés, vai atrapalhar ou ficar se metendo ou alguma coisa desse gênero. A gente fica com um pouco de receio no início, tem essa primeira impressão. Mas, depois que a gente já tem experiência, a gente vê que não é assim. Depois dessa primeira impressão eu não conseguiria me imaginar sem o trabalho do segundo professor na sala. Ele também fazia um trabalho maravilhoso, tanto com os alunos quanto com a turma no geral também. (suj. 09).

Quando recebi a notícia de que trabalharia com o segundo professor fiquei com muita expectativa, pois seria uma experiência nova. Após o contato com o segundo professor fiquei mais tranquila, pois percebi que ele era uma pessoa aberta para troca de ideias, que poderíamos trabalhar juntos, melhorando nosso planejamento. Diante desta realidade sentique foi uma experiência maravilhosa, aprendi muitas coisas novas e percebi que não estava sozinha para enfrentar as dificuldades, principalmente em relação à criança que apresentava deficiência. (suj. 14).

A experiência da docência compartilhada refletiu numa mudança de percepção por parte dos professores regentes sobre o trabalho do segundo professor. A proximidade com o segundo professor, de forma concreta e real, possibilitou a interação entre os professores, o diálogo, a troca de ideias, o conhecimento e a cooperação, ainda que, esse trabalho, na maioria das vezes, se constitua na atuação do segundo professor enquanto auxiliar e cuidador. Essas novas representações possibilitaram a compreensão da necessidade de uma nova postura por parte dos professores regentes diante do trabalho na docência compartilhada, refletindo na sua prática. Essa prática passa a reconhecer a importância do trabalho coletivo, colaborativo e em equipe, para que, de fato, se constitua inclusivo.

A complexidade do trabalho pedagógico, diante da inclusão escolar tem aludido, cada vez mais, à compreensão de que os professores não devem mais trabalhar sozinhos, mas sim, em equipe, dialogando sobre as situações limites e sobre as possibilidades que se apresentam no contexto 
da sala de aula e no contexto escolar. Sabe-se que não é uma tarefa fácil e que envolve a necessidade de compartilhar um espaço que, historicamente, se constituiu sobre o domínio de um único professor. Nesse sentido, o enfrentamento do desafio de trabalhar na ou para a diversidade requer uma relação de equipe, de conjunto, de completude, de compartilhar experiências e conhecimentos. Nessa nova perspectiva, os professores regentes precisam aprender a usar todos os recursos, principalmente, os humanos, trabalhando assim, junto aos alunos e aos professores especializados (Denari, 2013).

A categoria de análise dimensões da prática pedagógica na docência compartilhada propõe analisar a relação entre o segundo professor e o professor regente, considerando as características e funções do trabalho do segundo professor, bem como, as interações estabelecidas entre esses professores nas práticas pedagógicas em sala de aula. Essa categoria foi dividida em duas subcategorias: $\underline{0}$ segundo professor: características e funções (classe 4) e prática pedagógica: interações no contexto da sala de aula (classe 2). A partir do referencial teórico de análise TRS essa categoria concentra vários elementos que possibilitam conhecer a dimensão descritiva do objeto representado.

A subcategoria 0 segundo professor: características e funções apresenta os conteúdos que fazem referência ao trabalho do segundo professor apontando elementos que caracterizam a sua função e a forma como esse trabalho tem sido percebido pelo professor regente no contexto escolar.

Anterior a chegada do segundo professor, o trabalho pedagógico junto aos educandos com deficiência era considerado um trabalho muito difícil de ser realizado, pois os professores regentes não tinham conhecimento de como trabalhar, considerando as necessidades educacionais desses educandos. A ausência de uma formação específica, com temas que envolvam a diversidade e a inclusão escolar, desperta uma sensação de impotência e de não saber como agir diante das diferenças incorporadas à escola pelo processo de inclusão.

Antes dessa política eu trabalhei com um aluno com deficiência e eu achei bem ruim, bem complicado, porque ele não conseguia. A gente percebia que ele tinha uma deficiência. Então algumas vezes eu fui relapsa não dando atividades que ele poderia fazer. Na época a gente excluía, ele ficava à parte. É uma falha que a gente tem, mas era pela falta de conhecimento, a gente não sabia como trabalhar. (suj. 03).

Antes da chegada do segundo Professor eu fiquei praticamente uns 3 meses sozinha. Mas era um horror. Era muito ruim. Como fazer a criança acalmar? Ela gritava, sapateava, empurrava a mesa. Então eu não tinha como acalmar e nem como trabalhar com os demais alunos. (suj. 04).

Antes da chegada do segundo professor o trabalho era muito difícil. Conforme a gravidade do caso a turma saía perdendo em relação aos conteúdos e outros aspectos. (suj. 14)

Carente da formação específica, o professor fica ancorado àqueles conhecimentos que têm origem na sua história pessoal e social, na sua subjetividade, suas crenças, forjadas no âmbito de seus grupos de pertença e na cultura, sendo esses saberes incorporados ao trabalho por meio de mecanismos sociais (Cunha, 2015).Assim, muitas vezes o professor, por desconhecimento ou ancorado numa história e cultura escolar excludente, projeta um olhar discriminatório ao educando com deficiência.

A partir da chegada do segundo professor, o trabalho junto ao educando com deficiência, passa a ser considerado pelo professor regente, um trabalho mais tranquilo, possível de ser realizado e com menos dificuldades. O cenário caótico, até então figurado, torna-se mais harmonioso e controlado através da atuação desse 
profissional, que possibilitará um auxílio e uma atenção específica ao educando com deficiência na realização das atividades pedagógicas e de necessidades diárias.

Agora que tem o segundo professor mudou muita coisa. E penso que tenha que ter o segundo professor para trabalhar com a criança, porque quando o aluno tem esse apoio ao lado, ele faz as coisas, porque esse professor está puxando e cobrando as atividades. (suj. 11).

Agora, o que mudou foi o fato de você não estar mais sozinho, ter alguém para auxiliar nas atividades mais específicas, estar estimulando e instigando o aluno. (suj. 13).

Agora que temos o segundo o professor nosso trabalho está sendo bem mais eficaz, pois, temos o segundo professor para contribuir $e$ não deixamos nenhum aluno prejudicado. (suj. 14).

Apesar de reconhecerem a importância e a necessidade de ter o segundo professor para auxiliar na inclusão do educando com deficiência no contexto de sala de aula, os professores regentes percebem o trabalho do segundo professor como um trabalho novo, que ainda está iniciando, e por isso, os segundos professores ainda não tem um acúmulo de práticas nesta área, e a maioria não tem formação em educação inclusiva.

Se os professores tivessem mais tempo de experiência nesta prática, talvez seria mais possível uma integração. Mas até então, o que eu tenho vivido é a falta de experiência, de conhecimento e a individualização do trabalho. (suj. 02).

Vi experiências em que o segundo professor ficava um pouco mais reservado e acabava passando aquela impressão de que não queria se envolver muito com os outros alunos.
Preferia ficar com o seu aluno. (suj. 08).

A falta de conhecimento e experiência no âmbito da inclusão de educandos com deficiência, justificam uma prática pedagógica individualizada, por parte do segundo professor, voltada para o auxílio específico e cuidados junto ao educando com deficiência, demandando pouco envolvimento e responsabilidades para com a turma no geral.

Esse tipo de prática ancora-se nos modelos assistencialista e médico-terapêutico da Educação Especial, os quais tiveram forte influência no início dos trabalhos e atendimentos voltados às pessoas com deficiência. No modelo médico-terapêutico as categorias clínicas e terapêuticas se sobrepõem às pedagógicas. A estas práticas pedagógicas cabe a tarefa de atenção e correção das áreas prejudicadas através de procedimentos curativos, educativos e terapêuticos (Beyer, 2006).

Perceber o trabalho do segundo professor ancorado neste modelo é uma forma de torná-lo familiar, de incluí-lo numa categoria de "imagem comum" (Moscovici, 2003), historicamente construída ao longo da educação das pessoas com deficiência, possibilitando a atribuição de sentidos para a compreensão desse trabalho e para a condução da sua prática.

$\mathrm{O}$ fato de existirem legislações específicas e normatizações que definem e orientam o trabalho do segundo professor e suas funções como um trabalho pedagógico que deve acontecer de forma conjunta na sua regência, não garante que esses professores acessem e se apropriem desse conhecimento, de modo a colocá-los, de forma imediata, em prática. Destarte, não há como esperar que a experiência de docência compartilhada tenha sucesso apenas porque há uma legislação que a institui. Conforme Moscovici (2003) não é fácil transformar ideias, fatos e práticas não familiares em ideias, fatos e práticas usuais, próximas e atuais. É necessário, primeiro, darlhes uma feição familiar, identificando pontos 
de ancoragens, reduzindo-as a categorias e a imagens comuns, colocando-as em um contexto familiar.

Outro elemento apresentado por esta subcategoria refere-se à diferenciação do trabalho do professor regente e o trabalho do segundo professor. A maioria dos professores regentes entrevistados difere o seu trabalho do trabalho do segundo professor, destacando que, ao professor regente cabe a responsabilidade do trabalho junto à turma toda e ao segundo professor cabe $\mathrm{o}$ atendimento mais individualizado junto ao aluno com deficiência.

Eu percebo que, ainda, existe muito o segundo professor como cuidador. É mais cuidador do que professor, porque as crianças têm essa necessidade. Precisam primeiro do cuidador e depois do professor. (suj. 07).

O professor regente tem uma responsabilidade de trabalhar tudo, de dar conta das seis disciplinas e de todas as crianças. Corrigir provas, planejar, olhar caderno, comportamento, socialização. Penso que o segundo professor vai direcionar o olhar dele para aquela criança. (suj. 10).

Eu me sinto responsável por tudo. $O$ professor regente tem essa função de ser o professor que tem que conduzir os trabalhos. O professor regente é o responsável da turma e o segundo professor é uma pessoa que está ali para auxiliar. (suj. 13).

Os relatos demonstram que os professores regentes percebem o trabalho do segundo professor como um trabalho de auxiliar, de cuidador, direcionado ao atendimento individualizado do educando com deficiência. Nesse sentido, para o segundo professor e para o educando com deficiência, é organizada uma intervenção pedagógica e a ocupação de um espaço à parte no contexto da sala de aula, o que faz com que os modelos da escola tradicional não sejam alterados e nem colocados em conflito. Dessa forma, reproduzse um trabalho de segregação e de cuidados que ainda se faz presente na memória dos professores e que justificam as práticas pedagógicas individualizadas e dicotomizadas no contexto da escola regular. $O$ segundo professor pouco ou nada modifica no educando enquanto um sujeito aprendiz, pois seu papel é de zelo, controle, vigilância e adaptação do educando à realidade escolar.

A partir dessa visão, o segundo professor é percebido como uma pessoa que possui características especiais, como ser cuidadoso, atencioso e assistente. Essa representação de professor especial está ancorada na contextualização histórica do atendimento às pessoas com deficiência, onde os princípios assistenciais e terapêuticos permeavam os serviços institucionalizados, voltados para o atendimento dessas pessoas. A educação especial no Brasil caminhou de uma fase inicialmente assistencial, a qual, sob um olhar de caridade, visava o bem-estar da pessoa com deficiência, para uma fase médica - clínica e terapêutica, a qual priorizava os aspectos médicos e psicológicos (Ferreira, 1995; Mantoan, 2002; Beyer, 2006).

Os atributos selecionados para a construção de uma imagem do segundo professor são constituídos de uma visão emocional, afetiva e cuidadosa. Essa seleção implica na constituição de um esquema figurativo que representa o segundo professor como um profissional auxiliar, cuidadoso e especial, representando uma imagem romântica e assistencial desse professor. No entanto, a complexidade que constitui o contexto da escola e da sala de aula, a partir da perspectiva da educação inclusiva, requer um professor com intencionalidade pedagógica e comprometido com o planejamento pedagógico, com os processos de aprendizagem dos educandos e que domine os conhecimentos pertencentes a educação de pessoas com deficiência, assim como, os conhecimentos curriculares trabalhados no contexto de sala de aula. 
A subcategoria prática pedagógica: interações no contexto da sala de aula (classe 2), apresenta os elementos que fazem referência às práticas pedagógicas desenvolvidas pelos professores regentes e segundos professores no contexto da sala de aula. Referem-se, ainda, ao planejamento pedagógico, às adaptações das atividades e como acontece a interação entre os professores nesses processos.

Eu tenho que organizar os meus conteúdos, os meus conhecimentos, o que vou desenvolver com a turma. $O$ meu planejamento se dá um pouco distante da segunda professora, não sei se por minha culpa ou talvez dela também. Teria que ter tido um planejamento mais junto, ela teria que ter visto mais comigo, por exemplo: Professora o que você vai trabalhar agora? (suj. 01).

Eu digo para minha segunda professora que vamos trabalhar sobre a água, e ela vai procurar as atividades sobre a água que são possíveis para aquela criança desenvolver. Então nós não sentamos uma do lado da outra para combinar o que uma ou outra vai fazer, eu deixo ela buscar com autonomia. (suj. 10).

Os dados analisados revelaram que, para um pequeno grupo de professores regentes, a prática pedagógica desenvolvida pelos professores regentes e segundos professores, ainda acontece de forma fragmentada, assim como o planejamento e a seleção dos conteúdos e das atividades a serem desenvolvidas. Sendo que ao professor regente cabe a seleção e organização dos conteúdos, o planejamento das atividades e a intervenção junto aos educandos que não apresentam deficiência e, ao segundo professor, cabe a adaptação destes conteúdos e das atividades a serem desenvolvidas com os educandos que possuem deficiência.

No entanto, para um número significativo de professores regentes, a prática pedagógica, no contexto da sala de aula, deve acontecer de forma compartilhada, com o envolvimento dos dois professores, tanto nos processos de atuação, como também de planejamento e adaptação das atividades para todos os educandos.

Sobre a prática pedagógica, sempre foi bem positivo o trabalho com essa segunda professora. A gente antecipa o planejamento, eu repasso para ela o meu planejamento antecipado, para que ela possa organizar os materiais, a metodologia e os jogos. A gente, por várias vezes, conseguiu sentar juntas e planejar, ver como o aluno está se desenvolvendo e as atividades que estão dando certo. Então, no planejamento você tem que estar envolvendo os outros professores também. Juntas, eu e a segunda professora, tínhamos que dar conta de pensar e planejar algo juntas. (suj. 05).

A nossa prática pedagógica se dá numa relação de parceria sendo que temos duas horas atividades juntas e isso facilita. Sempre falamos do conteúdo a ser trabalhado semanalmente. (suj. 15)

Para a prática pedagógica temos um trabalho em conjunto. $O$ meu planejamento com a segunda professora, nós conversamos sobre os conteúdos que vamos trabalhar $e$ como adaptar. Tem que ter esse envolvimento e a responsabilidade perante os outros. Auxiliar também no processo de avaliação dos alunos. Quando tem que atribuir uma nota para os alunos eu pergunto para a segunda professora sobre o que ela acha. É preciso chamar para fazer parte, para ajudar a ver o que precisa para melhorar alguma criança. Não só com deficiência, mas alguma outra criança. Eu digo que o trabalho não é mais de uma pessoa, mas em dupla. (suj. 11). 
É nesse contexto de relações colaborativas que se configura a perspectiva da docência compartilhada. São encontros de saberes, fazeres, reflexões, metodologias, estratégias e recursos, por meio dos quais os professores se constituem sujeitos coletivos. A docência compartilhada nessa perspectiva caracteriza-se como um momento de diálogo, de troca entre os professores envolvidos, considerando os diferentes conhecimentos e experiências adquiridos no mundo plural e heterogêneo da sala de aula (Santos, 2007, citado por Jesus \& Effgen, 2012).

O desafio de trabalhar em contextos de inclusão escolar requer dos professores regentes e segundos professores, uma relação de equipe e trabalho colaborativo, por meio do compartilhamento de experiências, na busca de soluções, metodologias e estratégias criativas para lidar com as diferenças no contexto de sala de aula. Para tanto, o planejamento dos professores precisa estar voltado às práticas inclusivas que objetivam eliminar as barreiras de aprendizagem e interação. As ações e as práticas para desenvolver um ensino inclusivo, requer dos professores envolvidos, adaptações no planejamento, de modo que possibilite a participação dos educandos com ou sem deficiência, proporcionando a interação e a aprendizagem de todos os educandos (Soares, Javornik, \& Loss, 2019).

Essa compreensão requer professores teoricamente embasados para fundamentar suas escolhas e decisões metodológicas e pedagógicas. Esses saberes nem sempre são garantidos aos professores nos processos de formação inicial, por isso, é muito importante o investimento nos processos de formação continuada, que trate com solidez os aspectos gerais que permeiam a inclusão escolar, possibilitando que os professores percebam, na sua prática de docência, as necessidades especiais de seus alunos, assim como compreendam a educação a partir de um olhar inclusivo.

Diante destas considerações, Soares, Javornik e Loss (2019) destacam a importância de formar profissionais da educação conscientes de seu papel diante da atual realidade educacional. Professores reflexivos que se questionem se, suas práticas educativas estão segregando ou excluindo alguns educandos ou, se estão proporcionando inclusão, ou seja, se suas práticas, de fato, contemplam as diferentes necessidades explicitadas na sala de aula.

$\mathrm{Na}$ docência compartilhada, é fundamental considerar e valorizar a especificidade e a relevância do trabalho de cada professor na totalidade do trabalho pedagógico, superando, dessa forma, a prática de um trabalho pedagógico fragmentado, descontextualizado e dicotomizado.

\section{Considerações finais}

Este trabalho teve como objetivo identificar os elementos presentes na formação de representações sociais, por professores regentes de anos iniciais, sobre o trabalho do segundo professor, na perspectiva da Educação Inclusiva. A análise dos dados coletados permitiu estabelecer relações e considerações sobre as percepções e os sentidos que são atribuídos ao trabalho do segundo professor por parte dos professores regentes, apresentando as ancoragens e objetivações que estão na formação de suas representações.

À luz da Teoria das Representações Sociais foi possível compreender o trabalho do segundo professor como uma atividade que agrega uma valoração social constituída no contexto das interações e das práticas pedagógicas cotidianas. A inserção do segundo professor no contexto sócio-histórico-cultural permeado de tensões e de relações de forças que procuram construir identidades coletivas permitiu apreender o movimento de readaptação e reconstrução do contexto educativo e da prática pedagógica cotidiana, visando atender às demandas da inclusão escolar.

A percepção e a compreensão sobre o trabalho do segundo professor, sobre o seu posicionamento na relação pedagógica, na relação com aluno e na relação com o contexto 
escolar ainda estão em formação, pois existe num misto de crenças, opiniões e imagens que são compartilhadas, sendo algumas naturalizadas pelos contextos de exclusão e outras envolvidas nos discursos inclusivos.

Elementos apontaram para possibilidades de mudanças de representações a partir da relação, da vivência e interação entre os professores envolvidos na docência compartilhada, fato que contribui de forma positiva para o trabalho pedagógico junto aos educandos com deficiência e também para a revisão e reflexão das formas como esse trabalho vem sendo desenvolvido e compreendido.

Considerando que a atuação do segundo professor ainda é uma prática recente, percebemos que as imagens sobre este professor não estão totalmente definidas, uma vez que as percepções sobre esse trabalho ainda se apresentam muito diversas. O imaginário dos professores regentes está permeado por ancoragens que dotam o segundo professor de condições de controle, vigilância, auxílio e cuidados dos educandos com deficiência. Estas ancoragens constituem-se formas de proteção e manutenção de uma representação de professor regente que está cristalizada, sendo este professor constituído de um poder e detentor do saber e do trabalho pedagógico. Nesta perspectiva, apontamos para a necessidade do debate e da construção de uma prática escolar colaborativa, onde a ideia de equipe e de grupo se faz presente nos momentos de reflexões sobre os processos de inclusão, assim como, na prática inclusiva e partilhada da sala de aula.

Diante dos desafios da inclusão escolar, é preciso considerar a formação de representações pelos professores regentes a respeito do trabalho do segundo professor, pois estas representações se materializam nas práticas docentes, contribuindo para a efetivação de uma docência compartilhada, ou então, segregada, uma vez que as representações constituem-se em um saber efetivamente praticado, percebido em comportamentos, comunicações e práticas que ocorrem sistematicamente nos grupos sociais.

Esta pesquisa é relevante para a área da psicologia, ao analisar a formação de representações sociais sobre um novo profissional que surge na escola inclusiva, o segundo professor. Como é recente a contratação deste profissional na rede pública de ensino, a pesquisa e a produção de conhecimento científico sobre esta temática é escassa. Por isso, os resultados desta pesquisa poderão oferecer subsídios para formação continuada de profissionais que atuam com processos de ensino e aprendizagem de sujeitos com deficiência.

\section{Referências}

Amaral, L. A. (1995). Conhecendo a deficiência: em companhia de Hércules. São Paulo, SP: Robe Editorial.

Beyer, H. O. (2006). Inclusão e avaliação na escola: de alunos com necessidades educacionais especiais. Porto Alegre, RS: Mediação.

Brasil, Ministério da Educação. Secretaria de Educação Especial. (2010). Marcos Político-Legais da Educação Especial na Perspectiva da Educação Inclusiva. Brasília: Secretaria de Educação Especial.

Camargo, B. V., \& Justo, A. M. (2013). Tutorial para uso do software de análise textual IRAMUTEQ. Laboratório de Psicologia Social da Comunicação e Cognição -LACCOS. Universidade Federal de Santa Catarina, Brasil.

Recuperado de:

http://www.iramuteq.org/documentation/fi chiers/tutoriel-en-portugais.

Cunha, A. E. (2015). Representações sociais de professores acerca da inclusão escolar: elementos para uma discussão das práticas de ensino (Tese de Doutorado). Universidade Estácio de Sá, Rio de Janeiro. 
Denari, F. E. (2013). Diversidade, deficiência, autonomia escolar: de volta ao começo? In: S. E. S. de O. Martins, C. R. M. Giroto, \& C. B. G. Souza (Org.), Diferentes Olhares sobre a Inclusão (pp. 13-22). São Paulo, SP: Cultura Acadêmica; Marília: Oficina Universitária.

Ferreira, J. R. (1995). A Exclusão da Diferença. Piracicaba: UNIMEP.

Jesus, D. M. de, \& Effgen, A. P. S. (2012). Formação docente e práticas pedagógicas: conexões, possibilidades e tensões. In T. G. Miranda, \& T. A. G. Filho (org.), $O$ professor e a Educação Inclusiva: formação, práticas e lugares (pp. 17-24). Salvador, BA: EDUFBA.

Lei n. 17.143, de 15 de maio de 2017. Dispõe sobre a presença do Segundo Professor de Turma nas salas de aula das escolas de educação básica que integram o sistema estadual de educação de Santa Catarina. Recuperado de http://leis.alesc.sc.gov.br/html/2017/1714 3_2017_lei.html.

Mantoan, M. T.E. (2002). A Educação Especial no Brasil: da exclusão à Inclusão Escolar. In LEPED, Universidade Estadual de Campinas. Recuperado de: http://www.lite.fe.unicamp.br/cursos/nt/ta 1.3.htm

Mantoan, M.T. E. (2010). Atendimento educacional especializado: políticas públicas e gestão nos municípios. São Paulo, SP: Moderna.

Moscovici, S. (2003). Representações sociais: investigações em psicologia social. Petrópolis, RJ:Vozes.
Nova, T.de B. B., \& Machado, L. B. (2014). O processo de objetivação nas representações sociais de escola para crianças. Série-Estudos - Periódico do Programa de Pós-Graduação em Educação da UCDB, 38, 93-106. Recuperado de https://www.serieestudos.ucdb.br/serieestudos/article/view/746

Oliveira, A. A. S., Braun, P., \& Lara, P. T. (2013). Atendimento Educacional Especializado na área da Deficiência Intelectual: Questões sobre a prática docente. In S. G. C. Milanez, A. A. S. de Oliveira, \& A. R. N. Misquiatti (Orgs.), Atendimento Educacional Especializado para alunos com deficiência Intelectual e Transtornos Globais do Desenvolvimento (pp. 41-60). São Paulo, SP: Cultura Acadêmica; Marília, SP: Oficina Universitária.

Sassaki, R. K. (2005). Inclusão: o paradigma do século 21. Inclusão: Revista de Educação Especial, 1(1), 19-23.

Soares, N. G., Javornik, G. de A., \& Loss, A. S. (2019). Ações e Práticas de Ensino Inclusivas: Desafios da formação docente. In C. I. Ziesmann; J. de F. Batista; S. Lepke (orgs.), Formação Humana, Práticas Pedagógicas e Educação Inclusiva. Campinas, SP: Pontes Editores.

Stainback, S., \& Stainback, W. (1999). Inclusão: um guia para educadores (M. F. Lopes, Trad.). Porto Alegre, RS: Artmed.

Vala, J. (2006). Representações Sociais e Psicologia Social do Conhecimento Quotidiano. In J. Vala, \& M. B. Monteiro, Psicologia Social ( $7^{\mathrm{a}}$ Ed.). Lisboa: Fundação Calouste Gulbenkian. 


\section{Dados sobre as autoras:}

- Natalia Silveira Lima: Professora da Rede Pública Municipal de Concórdia-SC. Atua em Salas de Atendimento Educacional Especializado. Graduação em Educação Especial - UFSM, Especialização em Atendimento Educacional Especializado - UNESP/Marília, Mestre em Educação - UFFS- campus Chapecó/SC.

- Lísia Regina Ferreira: Docente da Universidade Federal da Fronteira Sul - Área de Psicologia da Educação. Atua nos cursos de Licenciatura e Mestrado em Educação, Doutora em Psicologia da Educação-PUC/RS.

Declaração de Direito Autoral

A submissão de originais para este periódico implica na transferência, pelos autores, dos direitos de publicação impressa e digital. Os direitos autorais para os artigos publicados são do autor, com direitos do periódico sobre a primeira publicação. Os autores somente poderão utilizar os mesmos resultados em outras publicações indicando claramente este periódico como o meio da publicação original. Em virtude de sermos um periódico de acesso aberto, permite-se o uso gratuito dos artigos em aplicações educacionais e científicas desde que citada a fonte conforme a licença CC-BY da Creative Commons. 